

\title{
International Journal of Technology Assessment in Health Care
}

\author{
Editor-in-Chief \\ Marjukka Mäkelä, M.D., Ph.D., M.Sc. \\ Research Professor, FINOHTA (Finnish Office for Health Technology Assessment) \\ at THL (National Institute for Health and Welfare) \\ P.O. Box 30 \\ 00271 Helsinki, Finland \\ Telephone: +358295247290 \\ Email: marjukka.makela@thl.fi
}

\begin{abstract}
Aims and Scope: The International Journal of Technology Assessment in Health Care has as its specific scope of interest the generation, evaluation, diffusion, and use of health care technology. It addresses the diverse audience of health care providers within medicine, public health, nursing, and the allied health professions; decision makers in government, industry, and health care organizations; and the scholarly disciplines such as ethics, economics, law, history, sociology, psychology, and engineering. The journal aims to fill the needs of those interested in the complexities of interaction between people and technology; technology as a force in social and organizational change; and technology as it is created, produced, applied, and paid for. It examines descriptively and analytically the effects of technology as perceived from the vantage point of different academic disciplines and policy-making organizations and examines methods necessary to conduct studies and evaluations of technology.

The focus of the journal is the international health care community. The experience of different countries in their encounter with health care technology, viewed comparatively, is invaluable to understanding its effects. Further, it is important to establish ties with the scholars, governments, and private institutions concerned with health care technology so that the experiences and learning of the international community in its parts can benefit the whole. The use of technology in health care has created some of the major dilemmas in society today. The journal serves as a forum for the wide range of professionals interested in the assessment of medical technology, its consequences for patients, and its impact on society.
\end{abstract}

Publishing, Advertising, and Subscription Offices: Cambridge University Press, 32 Avenue of the Americas, New York, NY100132473, U.S.A. (for U.S.A., Canada, and Mexico); or Cambridge University Press, Journals Fulfillment Department, UPH, Shaftesbury Road, Cambridge CB2 8BS, UK (for U.K. and elsewhere).

2015 Subscription Information: International Journal of Technology Assessment in Health Care (ISSN 0266-4623) is published bimonthly in February, April, June, August, October, and December by Cambridge University Press, 32 Avenue of the Americas, New York, NY 10013-2473; Cambridge University Press, The Edinburgh Building, Shaftesbury Road, Cambridge CB2 8RU, UK. Annual institutional subscription rates for Volume 31 (2015): Institutions online only US \$616.00, and online only UK and elsewhere £353.00. Individuals online only US \$295.00, and online only UK and elsewhere $£ 166.00$. Single part: US $\$ 113.00$ in the U.S.A., Canada and Mexico; UK $£ 65.00$ and elsewhere. Online only for all institutions. Print editions ceased in 2014. Back volume prices are available upon request. International Journal of Technology Assessment in Health Care and other Cambridge journals can be found at http://journals.cambridge.org

\section{(C) Cambridge University Press 2015}

All rights reserved. No part of this publicationmay be reproduced, in any form or by any means, electronic or otherwise, without permission in writing from Cambridge University Press. Policies, request forms, and contacts are available at: http://www.cambridge. org/rights/permissions.permission.htm

Permission to copy (for users in the U.S.A.) is available from Copyright Clearance Center, http://www.copyright.com, email: info@ copyright.com.

Postmaster: Send address changes in the U.S.A. and Canada to: International Journal of Technology Assessment in Health Care, Journals Department, Cambridge University Press, 100 Brook Hill Drive, West Nyack, NY 10994-2133, U.S.A. Send address changes elsewhere to: International Journal of Technology Assessment in Health Care, Cambridge University Press, Journals Fulfillment Department, UPH, Shaftesbury Road, Cambridge CB2 8BS, UK. 


\section{CONTENTS}

\section{Editorial}

1 Global pricing policies and cost-effectiveness of trastuzumab in Latin America Robert B. Giffin

\section{Assessments}

2 Implications of global pricing policies on access to innovative drugs: The case of trastuzumab in seven Latin American countries Andres Pichon-Riviere, Osvaldo Ulises Garay, Federico Augustovski, Carlos Vallejos, Leandro Huayanay, Maria del Pilar Navia Bueno, Alarico Rodriguez, Carlos José Coelho de Andrade, Jefferson Antonio Buendía and Michael Drummond

12 Introduction of innovative medical devices at French university hospitals: An overview of hospital-based health technology assessment initiatives

Nicolas Martelli, Mathilde Billaux, Isabelle Borget, Judith Pineau, Patrice Prognon and Helene van den Brink

19 Efficacy of Carpentier-Edwards pericardial prostheses: A systematic review and meta-analysis Carlos Alberto S. Magliano, Roberto M. Saraiva, Vitor Manuel P. Azevedo, Adriana M. Innocenzi, Bernardo R. Tura and Marisa Santos

27 Consumer preferences for scanning modality to diagnose focal liver lesions Jennifer Whitty, Alexandra Filby, Adam B. Smith and Louise M. Carr

36 Socio-ethical issues in Personalized Medicine: A systematic review of English language health technology assessments of gene expression profiling tests for breast cancer prognosis Sarah E. Ali-Khan, Lee Black, Nicole Palmour, Michael T. Hallett and Denise Avard

\section{Methods}

51 A novel search builder to expedite search strategies for systematic reviews Biren B. Kamdar, Pooja A. Shah, Sruthi Sakamuri, Bharat S. Kamdar and Jiwon Oh

54 Iterative sifting in the selection of research evidence: Implications for reviews and other decision problems Rachel Archer, Suzy Paisley, Munira Essat, Louise Preston and Martin Thornhill

59 Evidence requirements for reimbursement of pharmaceuticals across Europe Oyinlola Oyebode, Zoe Garrett, Elizabeth George, Agnese Cangini, Luisa Anna Adele Muscolo, Simone Warren, Bertalan Nemeth, Csenge Földesi, Marcela Heislerová and Eva Gajdošová

68 Framework for user involvement in health technology assessment at the local level: Views of health managers, user representatives, and clinicians Marie-Pierre Gagnon, Marie Desmartis, Johanne Gagnon, Michèle St-Pierre, Marc Rhainds, Martin Coulombe, Mylène Dipankui Tantchou and France Légaré

78 EuroScan International Network member agencies: Their structure, processes, and outputs Claire Packer, Sue Simpson and Rosimary Terezinha de Almeida

86 Medical device prices in economic evaluations Ilke Akpinar, Philip Jacobs and Don Husereau 
90 Payer perspectives on future acceptability of comparative effectiveness and relative effectiveness research Rachael Moloney, Penny Mohr, Emma Hawe, Koonal Shah, Martina Garau and Adrian Towse

99 Developing an $\mathrm{PAD}^{\circledR}$ application for data collection in a rheumatology research clinic

Hussam Kaka, Renise Ayearst, Maithy Tran, Zahi Touma, Maria Bagovich, Ophir Vinik, Mansour Somaily, Amir Haddad, Dafna D. Gladman and Vinod Chandran

\section{Policies}

103 A 10-year hospital-based health technology assessment program in a public hospital in Argentina Graciela Demirdjian 